\title{
Relationship of Selected Motor Fitness Components Percentage of Body Fat and Reaction Time
}

\author{
Abu Tareq* \\ Department of Sports Biomechanics, Bangladesh Krira Shikkha Protisthan (BKSP), Bangladesh \\ *Corresponding author: Abu Tareq, Senior Research Officer \& HOD, Department of Sports Biomechanics, Bangladesh Krira Shikkha Protisthan \\ (BKSP), Zirani, Savar, Dhaka, Bangladesh
}

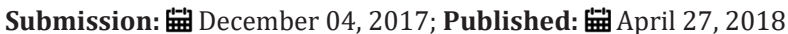

\begin{abstract}
The present investigation has been conducted to find out the relationship of selected motor fitness tests to percentage of body fat and reaction time (visual) in mid level male footballer players volunteered to participate in this study.16 students of 15 to 18 years of age and having training in BKSP, were recruited as the subjects. The data on the variables such as percentage of body-fat (BF), speed, agility and reaction-time (RT) were collected by using standard tools and techniques. Each subject's speed, agility, and reaction time were measured, and the data analyzed using Pearson's correlation and paired t tests (using SPSS-16). There were no meaningful correlations between reaction time and speed in the subjects .There was a negative correlation between percentage of body fat and reaction time.
\end{abstract}

Keywords: BKSP; Footballers; Speed; Agility; Reaction time and percentage of body fat

\section{Introduction}

The most popular and oldest sport in the world is football. It is a flexible sport offering the enjoyment of children, even in some sidestreet, school playground or park and for professionals competing at international level. Throughout history, football has been the most popular sport in Bangladesh [1] and is governed by the Bangladesh Football Federation (BFF). The issue of Bangladesh football has recently grown in its importance, recent development in the field of football have led to revamped the school, college, university, clubs, national and international level [2]. Riendeau (1958) using 61 young man from the armed forces as subject's examination the relationship. Between percentages of body fat and selected motor fitness tests. Significant negative correlations were found and the test items most affected by were those which involved running and jogging.

In a study of comparison of relationship between cardio vascular fitness and selected anthropometric measurements in eighth grade boys and college male subjects, yeast et al. [3] concluded that body composition adversely affected the performance in step test; however, age, height and lean body mass did not limit the performance. Scores in step test improved with higher percentage of lean body tissue. Book Walter et al. (1952) after investigating the relationship of physique, developmental level and physical fitness of Indian elementary school boys claimed that the body size and shape had an influence on physical performance.This boys of average size performed better than medium physique boys of average size and the very obese boys were the poorest physical performances. In a bi-racial study of relationship of anthropometric measurements to performance in standing broad jump, medicine ball put and zigzag run, nemour concluded that though Negro boys and girls had longer appendages and were taller than Caucasians, they were hat superior in the events of power and agility. Curoton \& kireil [4] in their study to find out the relationship of body fat to physical activities and fitness tests reached the conclusion that performance in strenuous physical activities are negatively correlated to the fat which proved to be handicap in most the exercises.

These individual differences will drastically influence physical performance. Thus they should be considered in judging their potentialities for participation in physical performance of mankind. For example high degree of meso morphs are generally favoured in many sports, the endomorphs on the other hand are definitely handicapped. Mature and longer boys have greater advantage over immature and short stature boys. Today one aspect of the scientific approach, which is receiving greater attention, is that of body composition more especially the measurement of the athlete's body composition to achieve optimal playing weight is gaining significance in the overall training programmed. By achieving the optimum weight, the athlete minimizes the negative effect of excess body fat on activity without sacrificing the required nutrition for successful performance.

Body composition is concerned in ports with the obesity of the individual. In measuring this aspect of body composition of the 
total body, weight and fat body weight. Lean body weight includes muscle, bone and vital organs. The under lying assumption is that total body weight equals lean body weight plus fat body weight. The higher the percentage of the body weight, the higher the degree of obesity. Body fat generally has been considered to a liability in the performance of motor activities. However, very few objective studies have been made which establish the direct relationship between body fat and the performance of various motor activities. Direct evidence of this nature would be very useful to show to the athletes and the non- athletes that excess of body fat negatively affects motor performance.

Studies published revealed that percentage of body fat, speed, agility, and reaction time has been the fundamental components of successful football performance [5]. Similarly, research studies have been sufficient evidence that in game situation, agility, reaction time and speed are the components of better performance of football players [6]. Very few researchers have been investigated percentage of body-fat and speed, agility and reaction-time separately and independently. Thus, there is no sufficient evidence to show the relationship among body fat percentage, with speed, agility, and reaction time of football players [7]. Similarly, there is no sufficient literature which revealed to what extent there is relationship exist between body-fat percentage, speed, agility, and reaction-time [8]. In conformity with this, in sufficient literature has been observed in Bangladesh context especially in football setting. As a result, the researchers aimed to investigate the relationship of selected motor fitness test (speed, agility) with percentage of body-fat and reaction-time of BKSP, Dhaka, Bangladesh $[9,10]$.

\section{Materials and Methods}

For the purpose of this study, sixteen male students from different classes of Bangladesh Institute of Sports were selected at random as subjects. The subjects were from football department. All the subjects were assembled in the track of BKSP and the research scholar explained the subjects voluntarily agreed to participate in the project in the interest of new scientific finding and for their personal assessment of variables chosen for the study. Body composition Percentage of BF were obtained by using skin fold calliper [11].

\section{Body fat}

The following were the sites used for taken skin fold measurements: 1. Biceps, 2. Triceps, 3. Sub scapular region, 4.
Supra- iliac region. The sum of the skin fold thickness of four sites of the body was converted into percentage body fat with the help of standard conversion table suggested by durnim and Rahman. From each subject's body weight, the weight of the fat possessed was calculated by using the following formula.

Fat weight $=($ Body weight $\times$ percentage value of fat $) / 100$ Percent lean body mass was obtained by subtracting percent value of fat from hundred

Weight: The weight of subjects was taken on a weighing machine. The subject wearing only shorts stood on the weighing machine and weight was recorded nearest to half a kilogram.

\section{$50 \mathrm{~m}$ speed test}

The subjects were asked to stand behind the starting line. Two subjects ran at a time. The starter gave the start by sounding the clapper using the command "on your mark" "set" and "clapper sound". At the sound of the clapper the subjects started running. The time recorded to the nearest $1 / 10^{\text {th }}$ of a second was the individuals score [12].

\section{Agility}

The subjects were asked to run the 10 meters distance 6 times ( $6 \times 10$ meter) and the time was recorded to the nearest one tenth of a second [13].

\section{Reaction time}

A software (Topendsports) was used to record RT of the subjects.

\section{Findings}

The data collected on sixteen subjects in respect of percentage of body fat, two physical performance items and reaction time was statistically analyzed using coefficient of correlation and data relating to this is presented in below tables.

\section{Discussion}

Table 1 shows positive correlations of reaction time to speed of movement and agility. But there is no significant relation among them. Table 2 shows highly significant negative correlation between reaction time and percentage of body fat. And Table 3 shows a positive correlation between percentage of body fat and speed of movement and a negative significant correlation between percentage of body fat and agility.

Table 1: Correlation between reaction time and selected motor fitness.

\begin{tabular}{|c|c|c|}
\hline S. No & Correlation & Correlation Coefficient(r) \\
\hline 1 & Reaction Time and Speed of Movement & 0.02 \\
\hline 2 & Reaction Time and Agility & 0.04 \\
\hline
\end{tabular}

*Significant at 0.05 level of confidence

Table 2: Correlation between reaction time and percentage of body fat $(\mathrm{BF})$.

\begin{tabular}{|c|c|c|}
\hline S No & Correlation & Correlation Coefficient(r) \\
\hline 1 & Reaction Time and Percentage of Body Fat & -0.31 \\
\hline
\end{tabular}

*Significant at 0.05 level of confidence 
Table 3: Correlation between percentage of body fat and selected motor fitness.

\begin{tabular}{|c|c|c|}
\hline S No & Correlation & Correlation Coefficient(r) \\
\hline 1 & Percentage of Body Fat and Speed of Movement & 0.02 \\
\hline 2 & Percentage of Body Fat and Agility & -0.1 \\
\hline
\end{tabular}

*Significant at 0.05 level of confidence

Analysis of data further shows that performance of speed of movement and agility has been found to be significantly related to reaction time. And relationship of percentage of body fat to agility and reaction time was negatively significant. This may be due to the higher fat and therefore fat will be able to work as a hindrance while performing the test. Since speed of movement was determined by the anaerobic capacity which in turn is directly proportional to percentage of body fat.

\section{References}

1. Melik J (2011) BBC News -Bangladesh football vies with cricket for sponsorship.

2. FIFA (2006) The general aspect of coaching, FIFA Coaching Manual.

3. Yoest, William E (1993) Relationship between cardio vascular fitness and selected anthropometric measurement of english eighth grade boys and girls college men.

4. Cureton TK, Kireil RW (1947) The relationship of external fat to physical education activities and fitness tests. Research Quarterly 18 (2): 123134.
5. Nepolion M, Rani U (2014) Predict of football playing ability on selected skill related Variables \& motor fitness variables of school level male football players. Indian Journal of Applied Research 4(5): 540-541.

6. John FG (2014) Agility training for athletic performance.

7. Chomiak J, Junge A, Peterson L, Dvorak J (2000) Severe injuries in football players: Influencing factors. Am J Sports Med 28(5): S58-S68.

8. Martens R (1997) Successful coaching. Human Kinematics, USA.

9. Carl WB (2013) The relationship of body size and shape to physical performance.

10. Joseph MS, Sengupta (1974) Body composition and endurance capacity of Indian hockey players. J Sports Med Phys Fitness 14(4): 272-277.

11. Benard N (1971) A comparative study of anthropometrical measurement of caucasian and negro boys and girls.

12. Welch BE, Crisp CE, Riendeaw RP, Brockett JE, Crowley LV (2013) Relationship of body fat to motor fitness test scores. Research quarterly 29: 200-203.

13. Wells L (1980) Body composition and aerobic requirements of male and female marathon runners.
Creative Commons Attribution 4.0

International License

For possible submissions Click Here

\section{Submit Article}

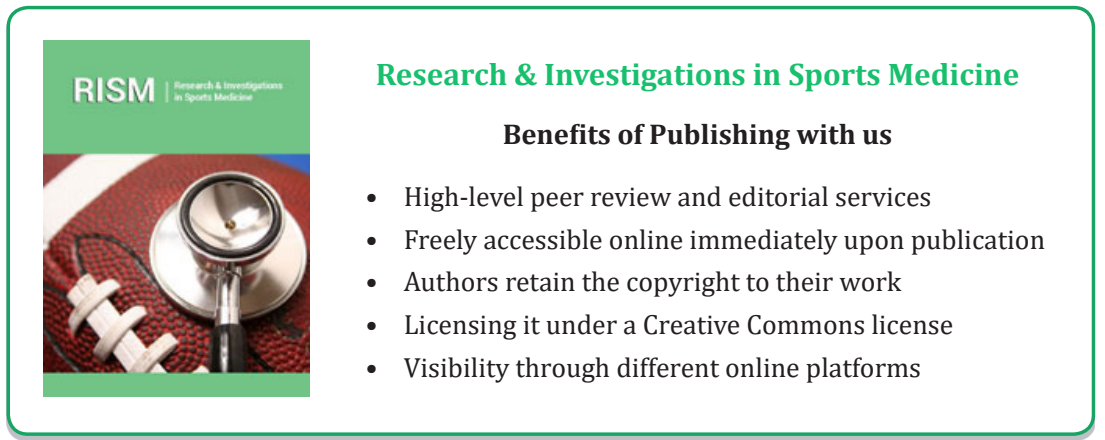

